\title{
The Transaction Characteristics of Forest Right Mortgage Loan and the Selection of Transaction Model
}

\author{
$\mathrm{Li} \mathrm{Li}^{1,2}$ Heliang Huang ${ }^{1, *}$ \\ ${ }^{1}$ College of Economics and Management, Fujian Agriculture and Forestry University, Fuzhou, Fujian 350000, \\ China \\ ${ }^{2}$ Jinshan College of Fujian Agriculture and Forestry University, Fuzhou, Fujian 350000, China \\ *Corresponding author. Email:hhh370@163.com
}

\begin{abstract}
Based on the theory of transaction cost economics, this paper analyzes the transaction characteristics of forest right mortgage loans. It is found that the forest right mortgage loan transactions of small-scale rural households have the characteristics such as high asset specificity, strong uncertainty and low frequency of individual transactions. According to the principle of matching transaction characteristics with governance structure, it is deduced that the forest right mortgage loan transaction model suitable for small-scale rural households are the "tripartite governance" transaction model, and the choice of transaction model in practice also confirms this point. At the same time, this paper analyzes the case of "Fulin Loan" in Sanming City. It is found that it adopts the tripartite transaction model of "rural households + forestry cooperatives + financial institutions", which effectively promotes the increase in the total amount of loans of rural households and the single-family loan, and reduces the loan interest rate. The single-family loan quota increased from 55,800 yuan in 2007 to 106,000 yuan in 2019; the monthly loan interest rate was reduced from over $8 \%$ to $5.9 \%$, achieving the effect of saving transaction costs by optimizing the transaction model.
\end{abstract}

Keywords: Forest right mortgage loan, Transaction characteristics, Transaction model, Tripartite governance.

\section{INTRODUCTION}

Due to the risk and uncertainty of forestry, the information asymmetry between financial institutions and rural households, and the lack of effective collateral for rural households, rural households have been subject to severe credit constraints from formal financial institutions for a long time. In order to solve this problem, since 2003, forest right system reform has been carried out in China's forest areas. Through clarifying

*Funds: Young and Middle-aged Teachers' Educational Research Project (Social Science) of Fujian Provincial Department of Education — "Research on the Impact of Financial Linkage on Forest Right Mortgage Loan Credit Rationing" (JAS20527); 2018 General Education and Teaching Reform Research Project of Fujian Provincial Undergraduate College - "Research on Evaluation of Innovation and Entrepreneurship Ability of Independent College Students Based on ABC-BP Model - Taking Jinshan College as an Example" (FBJG20180328). forest right, issuing forest right certificate, giving rural households forestry right, and promoting the capitalization of forestry right on this basis, a series of documents on promoting forest right mortgage loan have been issued by various departments. "Measures for Registration of Mortgage of Forest Resources Assets (Trial)" (2004), "Opinions on the Implementation of Forest Right Mortgage Loan" (2013) and so on have made clear the mortgage function of relevant forestry rights and promoted the rapid development of forest right mortgage loan. A series of measures aims to ease the credit constraints faced by rural households, but there are many problems in practice. The most important problem is that the beneficiaries of forest right mortgage loan are mainly large-scale forestry enterprises or forestry households, while the effect is not significant for small and medium-sized decentralized rural households [1]. In the 
exploration of the middle and late development of forest right mortgage loan, in order to adapt to the loan demand of small and medium-sized decentralized rural households, various regions have opened diversified innovation of forest right mortgage loan model. In practice, the more typical transaction models of forest right mortgage loan are as follows: "rural households + forestry cooperative + financial institutions", "rural households + guarantee company + financial institutions", and rural households' joint guarantee loan [2]. These transaction models belong to the "tripartite governance" transaction model, and all introduce the third party organization to conduct transaction governance. Why did the transaction model come into being? What transaction characteristics contributed to the formation of the transaction model? From the perspective of transaction cost economics, this paper analyzes the transaction characteristics of forest right mortgage loan according to the matching principle of transaction characteristics and governance structure in transaction cost economics, and further explores how the innovation of forest right mortgage loan transaction model of small and medium-sized rural households is formed under the constraints of its specific characteristics.

\section{THEORETICAL ANALYSIS FRAMEWORK OF TRANSACTION COST ECONOMICS}

\subsection{Transaction Characteristics and Transaction Costs [3]}

According to transaction cost economics, all transactions have transaction costs, which are determined by their transaction characteristics. Williamson believes that the transaction characteristics mainly include: asset specificity, uncertainty and transaction frequency. First of all, asset specificity refers to the degree of difficulty that an asset can be used for different purposes and used by different users without sacrificing its production value. Neve believes that the asset specificity in financial transactions is mainly related to the liquidity or conversion ability of assets [4]. Secondly, uncertainty includes the uncertainty of human behavior and the uncertainty of external environment. The uncertainty of human behavior mainly comes from bounded rationality and opportunism. Third, transaction frequency refers to the number of similar transactions in a certain period. According to the frequency, it can be divided into occasional transactions and regular repeated transactions. Among them, the higher the asset specificity is, the weaker the conversion ability is, that is, the higher the conversion cost and exit cost are, the higher the transaction cost is; the higher the uncertainty is, the more information search cost and supervision cost will be paid to reduce the risk brought by the uncertainty, and the higher the transaction cost is; the higher the transaction frequency is, the higher the transaction cost is, and the decentralization of repeated transactions of small-scale enterprises will lead to high transaction costs. The more frequent transactions can be managed by building a special governance structure. However, the premise of establishing a special governance structure is that its construction and operation costs need to be less than the income from repeated transactions in its special governance structure.

\subsection{Transaction Characteristics and the Choice of Governance Structures [5]}

In Williamson's transaction cost theory, there is no essential difference among the concepts of "contractual relationship", "governance structure" and "transaction model". Williamson believes that transactions are usually achieved through contractual relationship, and the governance clauses in contractual relationship regulate the decisionmaking process or renegotiation rules when the transaction model and relevant environment change, and then different governance structures are formed. Therefore, the choice of transaction model discussed in this paper is actually the choice of optimal governance structure. The selection of governance structure is carried out by comparing the transaction costs between different governance structures, and the transaction costs are determined by the transaction characteristics. Therefore, it is to select the governance structure that saves the transaction costs most by matching different governance structures with their corresponding transaction characteristics. According to the transaction cost economics and the degree of asset specificity and transaction frequency, if there is a high degree of uncertainty, the relationship between the transaction characteristics and the matched governance structure is shown in "Table 1" [5], [6]. 
Table 1. Matching transaction characteristics with governance structure

\begin{tabular}{|c|c|c|c|}
\hline \multirow{2}{*}{ Transaction frequency } & \multicolumn{3}{|l|}{ asset specificity } \\
\hline & non-specificity & medium-specificity & high level of specificity \\
\hline occasional & \multirow{2}{*}{$\begin{array}{l}\text { market governance } \\
\text { /classical contract }\end{array}$} & $\begin{array}{l}\text { tripartite governance } \\
\text { /neoclassical contract }\end{array}$ & $\begin{array}{l}\text { tripartite governance } \\
\text { /neoclassical contract }\end{array}$ \\
\hline repeated & & $\begin{array}{l}\text { two-way governance } \\
\text { /relational contract (exogenous) }\end{array}$ & \\
\hline
\end{tabular}

Forest right mortgage loan belongs to financial transaction, and it is also a subclass of transaction activities. The transaction model of forest right mortgage loan belongs to the content of governance structure. Therefore, the following part will be based on the theoretical framework of transaction cost economics. The following part mainly analyzes the transaction characteristics of forest right mortgage loan faced by small-scale rural households, and finds out the matching transaction model on this basis, so as to achieve the goal of saving the transaction cost of forest right mortgage loan, reducing the transaction risk and promoting the transaction.

\section{ANALYSIS ON THE TRANSACTION CHARACTERISTICS OF FOREST RIGHT MORTGAGE LOAN}

\subsection{As Mortgage Assets, Forest Assets Have High Asset Specificity}

The forest right in the forest right mortgage loan mainly refers to the "forest ownership and forestland usufruct" that can be used for mortgage. Usually, the forest ownership and forestland usufruct are mortgaged together, which is hereinafter referred to as "forest assets". As collateral, forest assets have high asset specificity, which is not conducive to transfer and realization. First of all, forest assets as collateral have strong specificity of geographical location. The geographical location of forest land is fixed, and its value is limited by the local market environment, natural environment, land fertility, natural disasters and other natural endowments. When the forest is attached to the forest land, the forest and forest land are mortgaged together. Therefore, the value of the collateral is naturally affected by the local market environment, forest land quality and natural environmental factors. Forest asset mortgage is constrained by geographical location specificity. Of course, the better the market environment, land quality and natural resources of the region where the fore integrated governance relational contract (endogenous) land is located, the weaker the geographical location specificity, and vice versa. Secondly, the scale and fragmentation of mortgaged forest land will affect its liquidity. The smaller the scale of forest land held by rural households, the more fragmented it is, and the less conducive it is to market circulation and scale effect as collateral. Small or fragmented forest land is suitable for transfer only between acquaintances or owners of adjacent plots. Therefore, from the perspective of financial institutions, accepting small-scale and fragmented forest land as collateral will face higher asset specificity and greater default risk. Thirdly, the circulation of forest assets is controlled by certain property rights, which reduces its liquidity. Due to the fixed location of forest land, the disposal of forest assets is affected by the property rights control policies such as the local cutting quota policy and the use limitation of forest land, as well as the local cutting cost, which limits the space scope, audience group and use of forest land circulation. From this point of view, forest assets still have strong asset specificity.

\subsection{The Transaction of Forest Right Mortgage Loan Has Great Uncertainty}

Firstly, forest assets have natural risk and market risk. Like all assets, the value of forest assets is affected by market factors, but at the same time, it is different from the traditional industrial assets as collateral. The forest right mortgage loan will face the possible natural risks, such as bad weather conditions, disasters, etc., which will lead to the decline or destruction of the value of the mortgage assets. With dual risks, the transaction has greater uncertainty. Secondly, it is difficult to supervise and evaluate forest assets. The composition of forest assets is complex, and there are many kinds of trees. At the same time, the production cycle of forestry is longer, and the maintenance methods of different trees in different production cycle are different. The forest assets as collateral are faced with the difficulties of conservation and supervision and the complexity of asset evaluation. The evaluation system of forest right mortgage loan is not perfect, and professional evaluation agencies and appraisers are in short 
supply, resulting in the inaccurate valuation and the increase in the uncertainty of the transaction. Third, the characteristics of rural households themselves, as borrowers, also aggravate the uncertainty of transactions. Most of the rural households have low education level, few financial knowledge, unstable source of income, limited wealth, lack of credit records, and the credit demands are decentralized and small-scale. These basic characteristics of rural households will also lead to the aggravation of information asymmetry between borrowers, thus increasing the uncertainty caused by opportunistic behaviors such as adverse selection and moral hazard.

\subsection{Transaction Frequency of Forest Right Mortgage Loan}

In the forest right mortgage loan, most of the loan needs of ordinary rural households are not completely related to forestry production and management, but are often related to their living needs. With scattered and small-scale operation characteristics, the overall number of rural households is large, the amount of a single transaction is small, the frequency of individual transaction is low, and the sustainable transaction in the later stage is also uncertain. As a result, the transaction cost between financial institutions and scattered rural households is higher, and the single transaction cost is higher. However, compared with ordinary rural households, large-scale forestry operators, such as forestry enterprises, mainly need funds for forestry production and operation. The transaction scale is larger, and the sustainable transaction in the later stage is more guaranteed. And the transaction cost is lower. This is also the reason why financial institutions are more willing to provide loans to large-scale operators.

\section{THE SELECTION OF THE TRANSACTION MODEL OF FOREST RIGHT MORTGAGE LOAN AND CASE ANALYSIS}

\subsection{The Selection of Transaction Model of Forest Right Mortgage Loan}

In the above analysis, the transaction of forest right mortgage loan has higher asset specificity. The smaller the scale of forest land is, the higher the degree of fragmentation is, and the worse the local market environment and land resource endowment are, the stronger the asset specificity is.
At the same time, there is high uncertainty in the transaction of forest right mortgage loan. When the transaction objects are ordinary rural households, the transaction will be faced with higher uncertainty due to the characteristics of rural households themselves, aggravating the problems of adverse selection, moral hazard and default risk. At the same time, higher asset specificity, greater uncertainty and lower individual transaction frequency make the transaction have huge transaction costs, and then the expected income of financial institutions for forest right mortgage loan will be greatly discounted. In practice, financial institutions as the supplier generally have low willingness to supply. As a result, forest right mortgage loan has limited alleviating effect on credit constraints for rural households. In fact, the governance of the transaction model of forest right mortgage loan is one of the ways to solve the current dilemma.

According to the above theoretical analysis on the relationship between transaction characteristics and governance structure and the transaction characteristics of ordinary rural households in financial institutions with high asset specificity, if the loan is promoted according to the way of market governance, it will inevitably present the dilemma of high transaction cost and high risk, and the transaction will be difficult to start. Therefore, according to the principle of matching transaction characteristics and governance structure, the transaction model suitable for small-scale rural households is the "third-party governance" transaction model. That is to say, through the participation of the third party, the third-party organization is rooted in the countryside and has natural advantages of the village affairs information, which will effectively help financial institutions to deal with liquidity risks, information asymmetry, opportunism and other problems caused by high asset specificity and high uncertainty, and reduce the cost of information search and the supervision and administration of financial institutions. At the same time, with the function of organizing and dispersing small-scale rural households by the third-party organization, the rural households are organized to form large-scale transactions, and the problem of high transaction costs caused by individual farmer' transactions with financial institutions can be solved. In practice, the current "tripartite governance" models are as follows: "financial institutions + forestry cooperatives + rural households", "financial institutions + guarantee companies + rural 
households", "financial institutions + government credit platform + rural households", and "forest farmers joint guaranty loan". The typical cases with better performance are "Fulin Loan" model, Yong'an model, Lishui model, etc. And then, there is a case study of Fulin Loan" in Sanming City.

\subsection{Case Analysis of "Fulin Loan"}

Sanming City is rich in forestry resources. The area of forestry land is $1.9 \times 10^{10} \mathrm{~m}^{2}$, accounting for $82.5 \%$ of the land area. However, $90 \%$ of the forest rights is in the hands of rural households. Therefore, the distribution of forest rights is relatively scattered, and the main body of management accounts for a relatively small proportion. If forestry farmers and financial institutions adopt the model of market governance to trade directly, the characteristics of high asset specificity, high uncertainty and so on will lead to high transaction costs and transaction risks, which will lead to the low supply willingness of financial institutions. In this context, Sanming Forestry Bureau and Sanming Rural Commercial Bank jointly launched "Fulin Loan", a new forestry financial product for small-scale forest households. The "Fulin Loan" model can be summarized as the "tripartite governance" model of "rural households + forestry cooperatives + financial institutions". The main participants are rural households, forestry professional cooperatives and financial institutions, in which the forestry cooperatives are the thirdparty organizations, which are responsible for the transactions between rural households and financial institutions. In addition, village committees, forestry stations and other grass-roots units also play a supporting role. The specific transaction process is as follows (see "Figure 1"). The forestry cooperatives strictly control the members of the cooperatives. When the rural households apply for the forest right mortgage loan, they mortgage the forestry assets of the same value to the cooperatives as counter guarantee, and the registration and filing of the mortgage counter guarantee is assisted by the township forestry station and the county real estate registration center. While the forestry cooperatives conduct credit evaluation and counter guarantee forest right asset evaluation on rural households, and provide guarantee for loans of forest farmers after confirming that the loans are qualified. Finally, the bank reviews the loans. At the same time, forestry cooperatives set up forestry guarantee fund, which is composed of "guarantee risk fund" and "villager risk fund", in which "villager risk fund" is jointly funded by cooperative members to provide guarantee for cooperative members' loans. If there is a breach of contract after the loan, the village committee and the forestry cooperative are jointly responsible for the centralized disposal of the mortgaged forest rights [7].

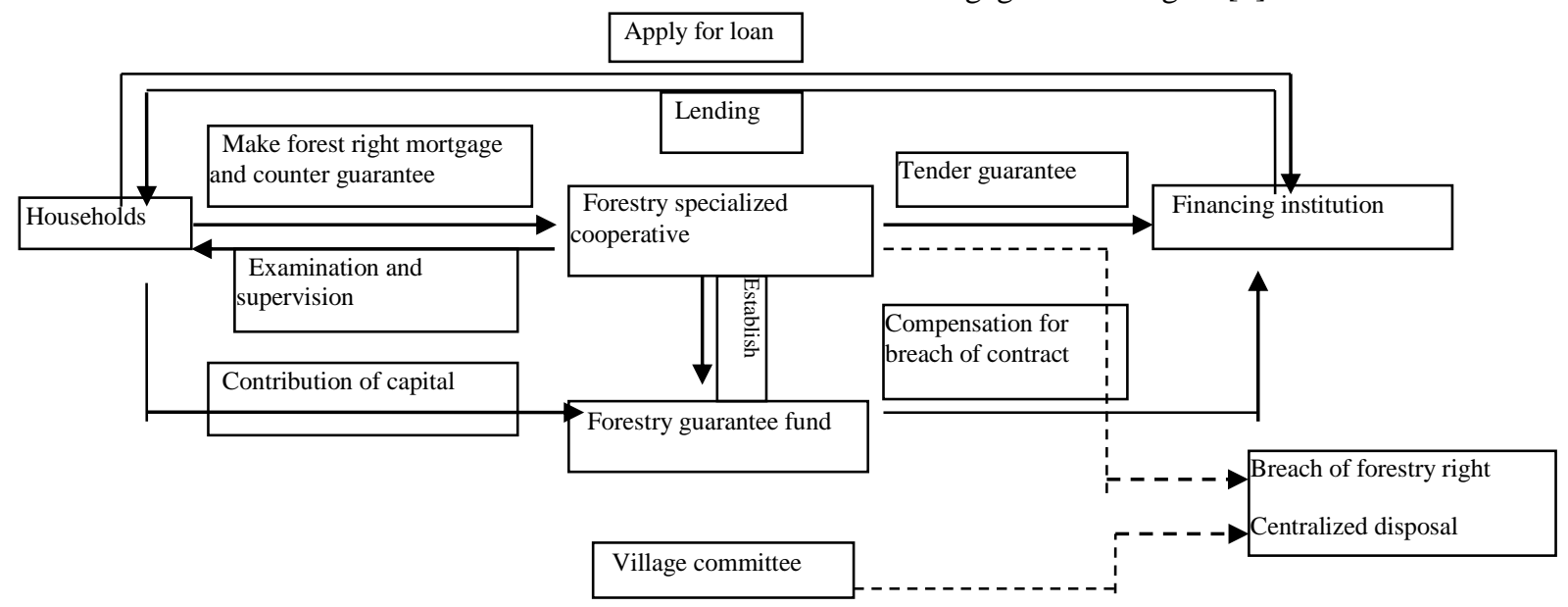

Figure 1 Diagram of transaction process of forest right mortgage loan of "Fulin Loan" in Sanming City.

Through the "tripartite governance" model, "Fulin Loan" model uses the forestry cooperatives to connect the financial institutions with the rural households. With the information advantages of the cooperatives, it carries out pre loan screening, review and post-loan supervision on the rural households, and uses the social advantages of the cooperatives and the village committee to be responsible for the centralized disposal of the default forest rights, which effectively solves the problem of high transaction cost and transaction risk caused by the high asset specificity and uncertainty of collateral. At the same time, through the organization function of the third-party forestry cooperatives, the scattered farmers can be organized, and the problem of large single 
transaction cost faced by the direct transaction between the scattered farmers and financial institutions can be solved through the scale effect. Under the tripartite governance model, the problems caused by the original transaction characteristics are effectively solved, and the enthusiasm of financial institutions to participate is improved. In practice, the amount of loans obtained by forest farmers is increased, and the loan interest is reduced. Firstly, both the total loan quota and the single-family loan quota have been increased. According to the regulations of forestry cooperatives, the loan limit of rural households can be increased by 10 times to 200000 yuan according to the guarantee fund invested by rural households, and the one-time credit period is 3 years. According to relevant data, "Fulin Loan" has been promoted in 96 villages in Sanming City since June 2017, and 77 villages have been granted loans, with a total loan amount of 68.81 million yuan. And 136,191 households in Sanming City are granted credit by the end of March 2019, with the credit amount of 13.6100 million yuan. The actual loans of 1.16 billion yuan have benefited 1,403 villages and 10,942 households, with an average loan amount of 106,000 yuan per household [8], which has been greatly improved compared to the average loan amount of 55,800 yuan per household under the "Fulin Loan" model that was not implemented in 2007 [9]. Secondly, the "tripartite governance" model reduces transaction costs, which is directly reflected in the decline in loan interest rates. The monthly loan interest rate must exceed $8 \%$ before using the "Fulin Loan". Through "Fulin Loan" model, the interest rate is reduced to $5.9 \%$. If there are rural households who comply with the forestry discount policy, additional subsidies can be obtained, which can reach a minimum of about $4 \%$.

\section{CONCLUSION}

From the perspective of transaction cost economics, this paper analyzes the transaction characteristics of forest right mortgage loan. It is found that when ordinary rural households have the forest right mortgage loan, there are characteristics of high asset specificity, high uncertainty, low individual transaction frequency and decentralized transaction. Therefore, it is suitable for small-scale and decentralized forest households to adopt "tripartite governance" transaction model of forest right mortgage loan. In other words, by adding the third-party organizations such as forestry cooperatives, village authorities and guarantee institutions, and using the information advantages and organizational functions of the third-party organizations, the problems of transaction costs and transaction risks caused by the direct transaction between households and financial institutions can be solved, so as to promote the alleviation of credit constraints on households. In the case study, it is concluded that the "tripartite governance" model makes the amount of single household and the overall amount of loan increased, and the loan interest rate decreased.

In order to further promote the development of forest right mortgage loan, save transaction cost and reduce transaction risk, relevant departments should also promote the development of forest right mortgage loan from the following aspects.

First, the further development of forest right mortgage loan also depends on the government's policy support and the development and improvement of forest land circulation market. The development and improvement of the marketoriented circulation of forest rights is conducive to improving the liquidity of mortgage assets, thus reducing the asset specificity of the transaction. Therefore, the government should further deploy relevant policies to promote the market-oriented circulation of forest property rights. At the same time, the variability of logging policy and forestry policy also increases the uncertainty of the transaction to a certain extent. Therefore, it is necessary for the government to take it into consideration when making policies, and gradually relax the quota for logging according to the needs, so as to ensure the stability and consistency of forestry policies and reduce the uncertainty. In addition, the government should promote the popularization of forest insurance so as to reduce the execution risk caused by uncontrollable risks such as natural risks.

Second, it is required to pay attention to control the additional transaction costs caused by the participation of the third-party organizations. It is required to consider the transaction cost of the third-party organization in the operation and supervision of the business when introducing the third-party organization in the "tripartite governance" model. The high transaction cost of the third-party organization will make the transaction model have no advantages in dealing with the forest right mortgage business. Therefore, it is better to pay attention to the boundary of the transaction cost paid by the third-party organization in the business to avoid excessive transaction costs. In the case, the forestry cooperative is not a third- 
party organization established specifically for the management of forest right mortgage loan. It has its own existence and other functions, and the business of processing forest right mortgage loan is only one of all its businesses. Moreover, the forestry cooperative itself is rooted in the local countryside, and has natural information advantages for the information search of borrowers. Therefore, the increase in forest right mortgage loan does not increase its additional asset investment or operating expenses, but only a small marginal cost when the transaction occurs. Similarly, when using other third-party organizations as intermediary organizations to link and cooperate with households and financial institutions, it is necessary to consider the impact of the participation of the intermediary organization on transaction costs to determine whether the third-party organization is a suitable third-party organization. Saving transaction cost and reducing transaction risk are the basic principles of choosing the third-party intermediary organization.

\section{AUTHORS' CONTRIBUTIONS}

$\mathrm{Li} \mathrm{Li} \mathrm{was} \mathrm{responsible} \mathrm{for} \mathrm{writing} \mathrm{the} \mathrm{paper,} \mathrm{and}$ Heliang Huang was responsible for collecting cases and revising the paper.

\section{REFERENCES}

[1] Gao Lu. Study on credit availability of forest right mortgage loans by farmer households [D]. Nanjing: Nanjing Forestry University, 2013: 43-44. (in Chinese)

[2] Sun Hong, Zhang Lezhu. The Institution Innovation for Forest Right Mortgage Loan [J]. Problems of Forestry Economics, 2016, 36(2): 133-138. (in Chinese)

[3] Neve. Financial System: Principles and Organization [M]. Beijing: Renmin University of China Press, 2005: 23-24. (in Chinese)

[4] Williamson O E. The Economic Institutions of Capitalism [M]. New York: Free Press, 1985.

[5] Williamson O E. Transaction Costs Economics: The Governance of Contractual Relation [J]. Journal of Law and Economics, 1979, 22: 233-262.

[6] Chen Dongping, Gao Mingzi. Third Party Enhanced Farmland Mortgage Contracts from the Perspective of Social Embeddedness of Transactions: A Case Study of Tongxin Model in Ningxia Province [J]. China Rural Survey, 2018(1): 70-83. (in Chinese)

[7] Hong Yanzhen, Fu Yonghai. Research on the Accessibility Factors of Forestry Tenure Mortgage Loan for Farm Households -Taking the "Fulin Loan" in Sanming City, Fujian Province as an Example [J]. Forestry Economics, 2018(9): 31-35, 39. (in Chinese)

[8] Sanming Daily. Sanming "Fulin Loan" revitalizes forest resources [EB/OL]. http://m.hxnews.com/news/fj/sm/201904/30/1 745372.shtml?from=singlemessage, 2019-430.

[9] Li Li, Huang Heliang, Wu Xiujuan. Study on the Behavior of Debtor and Lender in Forestry Property Mortgage - Case of Yong'an county [J]. Issues of Forestry Economics, 2008(1): 81-85. (in Chinese) 